\title{
Thidiazuron-enhanced biosynthesis and antimicrobial efficacy of silver nanoparticles via improving phytochemical reducing potential in callus culture of Linum usitatissimum $\mathrm{L}$.
}

\author{
This article was published in the following Dove Press journal: \\ International Journal of Nanomedicine \\ 22 February 2016 \\ Number of times this article has been viewed
}

\author{
Sumaira Anjum \\ Bilal Haider Abbasi \\ Department of Biotechnology, \\ Quaid-i-Azam University, \\ Islamabad, Pakistan
}

Correspondence: Bilal Haider Abbasi Department of Biotechnology, Quaid-i-Azam University, Islamabad 45320, Pakistan Tel +92 5I 9064 4I2I Email bhabbasi@qau.edu.pk

\begin{abstract}
Green synthesis of silver nanoparticles (AgNPs) by using plants is an emerging class of nanobiotechnology. It revolutionizes all domains of medical sciences by synthesizing chemical-free AgNPs for various biomedical applications. In this report, AgNPs were successfully synthesized by using whole plant extract (WPE) and thidiazuron-induced callus extract (CE) of Linum usitatissimum. The phytochemical analysis revealed that the total phenolic and flavonoid contents were higher in CE than that in WPE. Ultraviolet-visible spectroscopy of synthesized AgNPs showed a characteristic surface plasmon band in the range of 410-426 nm. Bioreduction of CE-mediated AgNPs was completed in a shorter time than that of WPE-mediated AgNPs. Scanning electron microscopy showed that both types of synthesized AgNPs were spherical in shape, but CE-mediated AgNPs were smaller in size (19-24 nm) and more scattered in distribution than that of WPE-mediated AgNPs (49-54 nm). X-ray diffraction analysis confirmed crystalline nature (face-centered cubic) of both types of AgNPs. Fourier-transform infrared spectroscopy revealed that the polyphenols and flavonoids were mainly responsible for reduction and capping of synthesized AgNPs. Energy dispersive X-ray analysis further confirmed the successful synthesis of AgNPs. Moreover, the synthesized AgNPs were found to be stable over months with no change in the surface plasmon bands. More importantly, CE-mediated AgNPs displayed significantly higher bactericidal activity against multiple drug-resistant human pathogens than WPE-mediated AgNPs. The present work highlighted the potent role of thidiazuron in in vitro-derived cultures for enhanced biosynthesis of chemical-free AgNPs, which can be used as nanomedicines in many biomedical applications.
\end{abstract}

Keywords: silver nanoparticles, Linum usitatissimum L., in vitro cultures, thidiazuron, antimicrobial, multidrug-resistant bacteria

\section{Introduction}

Synthesis of metallic nanoparticles is a gigantic and an expanding area due to their potential applicability in numerous fields such as electronics, optoelectronics, functional biology, drug delivery, antimicrobials, and biosensors. ${ }^{1}$ Numerous research techniques for the production of metallic nanoparticles through different physical and chemical methods are presented by the scientists. However, these synthetic methods, involving different chemicals, are expensive and may lead to the presence of noxious chemical species tangled on the surface of nanoparticles, which may have adverse effects in various biological and biomedical applications. ${ }^{2,3}$ This increases the growing need to develop environment-friendly procedures for synthesis of metallic nanoparticles through 
"green synthesis" and other new biological approaches. ${ }^{4}$ Synthesis of metallic nanoparticles by plant extracts is the most implemented method of green, eco-friendly fabrication of nanoparticles and also has a distinctive advantage that plants are extensively distributed, easily accessible, less biohazardous, and act as a source of numerous metabolites. ${ }^{5,6}$ Among the metallic nanoparticles, silver nanoparticles (AgNPs) represent one of the most comprehensively studied nanomaterials and the most favorite target of the aforementioned "green" methods, which fascinate scientists due to their distinctive antimicrobial properties. ${ }^{7}$ Due to the emergence of infectious diseases and antibiotic resistance in pathogenic microorganisms, pharmaceutical industries and scientists are looking for new antimicrobial agents, and AgNPs are the most promising contenders for antimicrobial action. Broad-spectrum bioactivities of AgNPs make them promising agents not only in fighting infections but also in tackling serious issues of tumors and, particularly, multidrug-resistant cancer cells. ${ }^{8}$

Plant extracts are believed to act as reducing and capping agents in the synthesis of nanoparticle due to the presence of bioactive compounds. The nature of plant extract affects the kind of nanoparticles synthesized in a highly critical manner, with the source of plant extract being the most vital factor affecting the morphology of synthesized nanoparticles. ${ }^{9}$ Interestingly, this is so because different plant extracts contain different amounts of biochemical reducing agents. ${ }^{10}$ Use of extracts from various plant parts, such as fruits, stems, bark, seeds, and latex, has been reported for the green synthesis of AgNPs. ${ }^{4,11-13}$ Unfortunately, very few reports are available on the role of in vitro-derived cultures of plants in the synthesis of AgNPs. ${ }^{14-16}$

The exploitation of plants in in vitro cultures is an opportunity to diversify these sources of biochemical reducing agents, which are either produced in limited quantities in wild plants or difficult to synthesize commercially in laboratories. ${ }^{17}$ Different plant growth regulators (PGRs) are used in in vitro cultures of plants to stimulate the production of phytochemicals. ${ }^{18,19}$ Among the different PGRs, thidiazuron (TDZ) is comparatively a better bioregulator of plant morphogenesis and is of immense importance since it has shown a dual activity of auxins and cytokinins. ${ }^{20,21}$ TDZ has a significant stimulatory effect on the enhancement of phytochemicals, which act as reducing and stabilizing agents. ${ }^{22}$

Linum usitatissimum L., is one of the oldest cultivated annual crops, which is not only commercially important but also has a long history of medicinal uses due to the presence of bioactive components, such as phenolic acids, flavonoids, polyunsaturated fatty acids, dietary fiber, and proteins. $^{23,24}$ The bioactivity of L. usitatissimum is mainly due to lignans (polyphenols), which are an important class of plant secondary metabolites and have been linked to the prevention and treatment of cardiovascular disorders, hypercholesterolemia, diabetes, diarrhea, and breast and colon cancers. ${ }^{25-29}$ In the present study, a novel approach for the synthesis of AgNPs has been described by using silver nitrate solution (SNS) in the presence of two different types of in vitro-derived extracts of L. usitatissimum, that is, whole plant extract (WPE) and callus extract (CE). The major goal of this study was to develop a rapid and safe method for biosynthesis of AgNPs. Synthesized AgNPs were further characterized by different techniques, and their antibacterial efficacy was evaluated against multiple drug-resistant human pathogens (Escherichia coli, Klebsiella pneumoniae, and Staphylococcus aureus). Furthermore, we have also explored the potential role of TDZ in in vitro-derived cultures in the biosynthesis of AgNPs. To the best of our knowledge, this is the first study that utilizes the in vitro-derived cultures of L. usitatissimum for the biosynthesis of AgNPs.

\section{Materials and methods}

\section{Seed germination and collection of plantlets}

Seeds of L. usitatissimum L. (brown variety) were collected and provided by Dr Nisar Ahmad, Assistant Professor at University of Swat, Pakistan. Seeds were surface sterilized according to the method of Ali and Abbasi, ${ }^{30}$ with some modifications. Briefly, seeds were washed with running tap water and then immersed in $1 \%$ mercuric chloride solution for 1 minute and in 70\% ethanol for 2 minutes, followed by washing three times with autoclaved distilled water. Then, the seeds were carefully dried on sterilized filter papers inside a laminar flow bench and placed onto Murashige and Skoog basal medium (MS0) ${ }^{31}$ containing $30 \mathrm{~g} \mathrm{~L}^{-1}$ sucrose and $8 \mathrm{~g} \mathrm{~L}^{-1}$ agar as solidifying agent. The $\mathrm{pH}$ of all media was adjusted to 5.6 , and the media were autoclaved at $121^{\circ} \mathrm{C}$ for 20 minutes. Inoculated flasks were placed in a growth chamber at $25^{\circ} \mathrm{C} \pm 2{ }^{\circ} \mathrm{C}$ for a 16 hours light $/ 8$ hours dark photoperiod with light intensity of $40 \mu \mathrm{mol} \mathrm{m} \mathrm{m}^{-2} \mathrm{~s}^{-1}$. After 25 days of inoculation, we collected in vitro-derived plantlets of L. usitatissimum for extract preparation and stem explants for callus induction.

\section{Establishment of callus culture}

For callus induction, $\sim 1-2 \mathrm{~cm}$ of stem explants lacking nodules were inoculated on $\mathrm{MS}^{31}$ media containing $30 \mathrm{~g} \mathrm{~L}^{-1}$ sucrose and $8 \mathrm{~g} \mathrm{~L}^{-1}$ agar, along with varying concentrations (0.5 mg L ${ }^{-1}, 1.0 \mathrm{mg} \mathrm{L}^{-1}, 2.0 \mathrm{mg} \mathrm{L}^{-1}, 3.0 \mathrm{mg} \mathrm{L}^{-1}, 4.0 \mathrm{mg} \mathrm{L}^{-1}$, and $5.0 \mathrm{mg} \mathrm{L}^{-1}$ ) of TDZ. The $\mathrm{pH}$ of the media was adjusted to 5.6-5.7 prior to autoclaving, and the cultures were 
maintained at $25^{\circ} \mathrm{C} \pm 2{ }^{\circ} \mathrm{C}$ for $16 / 8$ hours photoperiod in the growth chamber. For each concentration of TDZ, three explants were placed in a conical flask as one replicate, and the whole experiment was performed with three replicates. Callus induction frequencies were recorded on a weekly basis, and the calli emerged from the explants were collected after 5 weeks of inoculation for extract preparation.

\section{Extract preparation}

Approximately $10 \mathrm{~g}$ of each in vitro-derived whole plantlets and callus obtained in response to $2.0 \mathrm{mg} \mathrm{L}^{-1} \mathrm{TDZ}$ (yielding the highest phytochemical contents) culture of L. usitatissimum were separately mixed with $100 \mathrm{~mL}$ of distilled water and boiled for 15 minutes in a $500 \mathrm{~mL}$ Erlenmeyer flask. The extracts thus formed were cooled down to room temperature and filtered through a filter paper, and the volume of the filtrates was adjusted to $100 \mathrm{~mL}$ with distilled water (Figure 1) and stored at $4^{\circ} \mathrm{C}$ for further use.

\section{Determination of total phenolic and flavonoid content}

Total phenolic content (TPC) was determined using FolinCiocalteu's reagent according to the method described by Velioglu et al. ${ }^{32}$ Absorbance was measured at $725 \mathrm{~nm}$ using ultraviolet-visible (UV-vis) HALO DB-20 spectrophotometer (Dynamical Ltd, Victoria, Australia). The calibration curve $\left(0-50 \mu \mathrm{g} \mathrm{mL}^{-1}, R^{2}=0.968\right)$ was plotted using gallic acid as standard. All determinations were performed in triplicate, and the TPC was expressed as $\mathrm{mg} \mathrm{g}^{-1}$ gallic acid equivalents of dry weight (DW). Total flavonoid content (TFC) was determined using aluminum chloride colorimetric method as described by Chang et al. ${ }^{33}$ Absorbance of the reaction mixtures was measured at $415 \mathrm{~nm}$ by using UV-Vis HALO DB-20 spectrophotometer. The calibration curve $\left(0-40 \mu \mathrm{g} \mathrm{mL}{ }^{-1}\right.$, $R^{2}=0.998$ ) was plotted using quercetin as standard. The TFC was expressed as quercetin equivalents $\mathrm{g}^{-1}$ of DW.

\section{WPE- and CE-mediated biosynthesis of AgNPs}

Aqueous extracts (WPE and CE) of L. usitatissimum were mixed separately with SNS (1 mM) in different ratios $(1: 1 \mathrm{v} / \mathrm{v}, 1: 2 \mathrm{v} / \mathrm{v}, 1: 5 \mathrm{v} / \mathrm{v}$, and 1:10 v/v) to find out the appropriate concentrations of SNS for optimal AgNP biosynthesis. Briefly, $100 \mu \mathrm{L}$ of each extract was mixed separately with $100 \mu \mathrm{L}$ of SNS (1:1 ratio) and subsequent mixtures were prepared by increasing the SNS volume up to $1,000 \mu \mathrm{L}$. These mixtures were prepared in $1.5 \mathrm{~mL}$ Eppendorf tubes, and the reactions were allowed to progress at room temperature for different time periods. The bioreduction of silver ions was observed by change in the color of the reaction mixtures during different time intervals ( 0 minute, 10 minutes, 20 minutes, 30 minutes, 1 hour, 2 hours, 6 hours, 12 hours, and 24 hours). All experiments were carried out in triplicates and representative data are presented here.
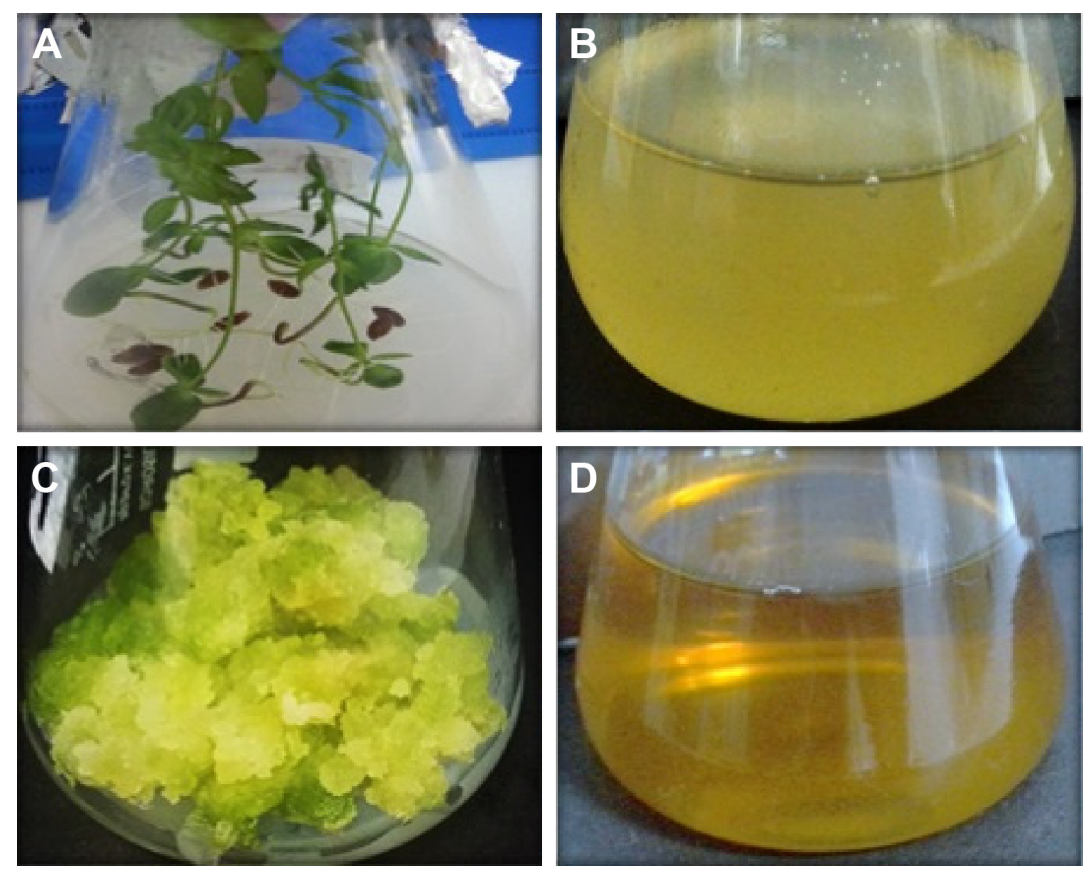

Figure I In vitro-derived cultures and extracts of Linum usitatissimum.

Notes: (A) Whole plantlets obtained from seeds germinated on MSO. (B) Aqueous whole plantlets extract. (C) Callus induced from stem explant in response to 2.0 mg $\mathrm{L}^{-}$ of TDZ. (D) Aqueous TDZ-induced callus extract.

Abbreviations: MSO, Murashige and Skoog basal medium; TDZ, thidiazuron. 


\section{Characterization of AgNPs}

UV-vis spectrophotometry

AgNP biosynthesis was monitored by recording UV-vis spectra $(\lambda=300-750 \mathrm{~nm})$ as a function of time on a HALO DB-20 spectrophotometer. The reaction mixtures showing optimal biosynthesis of AgNPs were further ensued by pelleting and washing AgNPs to remove unreacted SNS and plant extracts. Briefly, $1 \mathrm{~mL}$ of each reaction mixture was centrifuged at 12,000 rpm for 10 minutes at room temperature. Supernatants were discarded, and the AgNPs pellets were resuspended in $1 \mathrm{~mL}$ of distilled water, followed by centrifugation at $12,000 \mathrm{rpm}$ for 10 minutes. This process of washing was repeated three times, and the resulting AgNPs were air-dried to evaporate excessive liquid and used for further characterization.

\section{Fourier-transform infrared spectroscopy}

Fourier-transform infrared (FTIR) spectra of the WPE- and CE-mediated AgNPs were recorded using Perkin-Elmer model in the transmittable mode at the range of 3,500$500 \mathrm{~cm}^{-1}$ in potassium bromide $(\mathrm{KBr})$ pellets to find out the possible functional groups involved in the reduction and stabilization of AgNPs. Each sample was recorded with $\mathrm{KBr}$ pellets on an FTIR spectroscope at room temperature.

\section{X-ray diffraction analysis}

The crystalline structures of the synthesized AgNPs were investigated by X-ray diffraction (XRD). Powdered samples were used, and the diffraction patterns were recorded in the scanning mode on a Shimadzu-Model XRD 6000 operated at $40 \mathrm{kV}$ with a current of $30 \mathrm{~mA}$ and $\mathrm{Cu} / \mathrm{K} \alpha$ radiation in the range of $20^{\circ}-80^{\circ}$ in $2 \theta$ angles. The average particle size of the synthesized AgNPs was calculated using the DebyeScherrer equation. ${ }^{34}$

$$
D=\frac{k \lambda}{\beta \cos \theta}
$$

where $k$ is the shape factor (0.94), $\lambda$ is the X-ray wavelength ( $\lambda=1.5418 \AA$ ), $\beta$ is the full width at half maximum in radians, and $\theta$ is the Bragg's angle.

\section{Scanning electron microscopy and energy dispersive X-ray analyses}

The morphology of both types of synthesized AgNPs (WPE and CE mediated) was observed by scanning electron microscopy (SEM) by using the SIGMA model (MIRA3; TESCAN Brno, s.r.o., Brno, Czech Republic) operated at an accelerating voltage of $10 \mathrm{kV}$. The samples were prepared on a carboncoated copper grid by simply dropping a very small amount of the samples on the grid. The film was then allowed to dry under a mercury lamp for 5 minutes, and the SEM images were collected at different magnifications. For elemental analysis, the AgNPs were dried and drop-coated onto carbon film. Energy dispersive X-ray (EDX) analysis was then performed using the EDX detector attached with SEM.

\section{Antimicrobial activities of AgNPs against multiple drug-resistant bacteria}

S. aureus (ATCC-6538), E. coli (ATCC-15224), and K. pneumoniae (ATCC-4619), obtained from the American Type Culture Collection (ATCC), Manassas, VA, USA, were used for this experiment. This study was approved by the ethical committee of the Department of Biotechnology, Quaid-i-Azam University, Islamabad, Pakistan. The in vitro antibacterial activity was analyzed out with WPE- and CE-mediated AgNPs by well diffusion method. Briefly, the dried AgNPs were weighed $\left(10 \mathrm{mg} \mathrm{mL}^{-1}\right)$ and dissolved in sterile distilled water and used immediately. Three highly multiple drug-resistant bacterial strains, namely, E. coli, $K$. pneumoniae, and $S$. aureus, were used for assessing the antibacterial activity. The inoculums were prepared by growing a single colony overnight in nutrient broth. The nutrient agar plates were swabbed with bacterial strain broth, and $15 \mu \mathrm{L}$ of each synthesized AgNPs ( $\left.10 \mathrm{mg} \mathrm{mL}^{-1}\right), 1 \mathrm{mM} \mathrm{SNS}$ (positive control), commercial antibiotic as standard (ampicillin disk, $10 \mathrm{mg}$ ), WPE, and CE (negative control) were added in the wells. The plates were incubated at $37^{\circ} \mathrm{C}$ for 24 hours in an incubator, and the zone of inhibition ( $\mathrm{mm}$ ) was measured. Data were collected from three independent experiments for each strain, and each experiment was repeated three times.

\section{Statistical analysis}

All experiments were conducted in triplicate unless otherwise specified. Mean values of various treatments were subjected to analysis of variance, and significant difference was separated using Duncan's multiple range test. ${ }^{35}$ SPSS (Windows Version 7.5.1, SPSS Inc., Chicago, IL, USA) was used to determine the significance at $P<0.05$.

\section{Results and discussion Phytochemical analysis}

L. usitatissimum is known to be a rich source of bioactive compounds (flavonoids and phenolics) that might play a substantial role in the reduction and stabilization of AgNPs. Phytochemical analysis of WPE and CE of L. usitatissimum 
revealed significant variations in TPC and TFC. In the case of CE, maximum levels of TPC (5.10 $\left.\mathrm{mg} \mathrm{g}^{-1} \mathrm{DW}\right)$ and TFC (2.72 $\mathrm{mg} \mathrm{g}^{-1} \mathrm{DW}$ ) were found in response to $2.0 \mathrm{mg} \mathrm{L}^{-1}$ TDZ, whereas lower levels of TPC and TFC were found in response to all other applied concentrations of TDZ (Figure 2). Therefore, callus induced by $2 \mathrm{mg} \mathrm{L}^{-1} \mathrm{TDZ}$ which accumulated higher levels of phenolic and flavonoid content, was used for biosynthesis of AgNPs. However, in the case of WPE, the TPC (3.42 $\left.\mathrm{mg} \mathrm{g}^{-1} \mathrm{DW}\right)$ and TFC (1.61 $\mathrm{mg} \mathrm{g}^{-1} \mathrm{DW}$ ) were found to be significantly lower than those of $\mathrm{CE}$. This might be due to the young mass of cells with different ploidy levels in the callus, which may be metabolically active to produce various types of phytochemicals responsible for the bioreduction of metal atoms. ${ }^{8,14}$ Additionally, TDZ is an important PGR, which had been reported for the production of important bioactive compounds in many plant species. ${ }^{20,21}$ The variation in the production of these phytochemicals in response to different concentrations of TDZ can be due to the activation or the inhibition of key enzymes phenylalanine ammonia lyase and tyrosine ammonia lyase, which are crucial for biosynthetic pathways of these phytochemicals. ${ }^{36}$

\section{WPE- and CE-mediated biosynthesis of AgNPs}

Many studies have shown that the bioactive compounds, such as flavonoids, tannins, phenolics, amides, and proteins, present in plants act as reducing and capping agents. , $^{3,6,637,38}$ Since the WPE- and TDZ-induced CE of L. usitatissimum contain high levels of polyphenols and flavonoids, we expect that they will serve as reducing and capping agents for the biosynthesis of AgNPs. Therefore, we synthesized AgNPs using

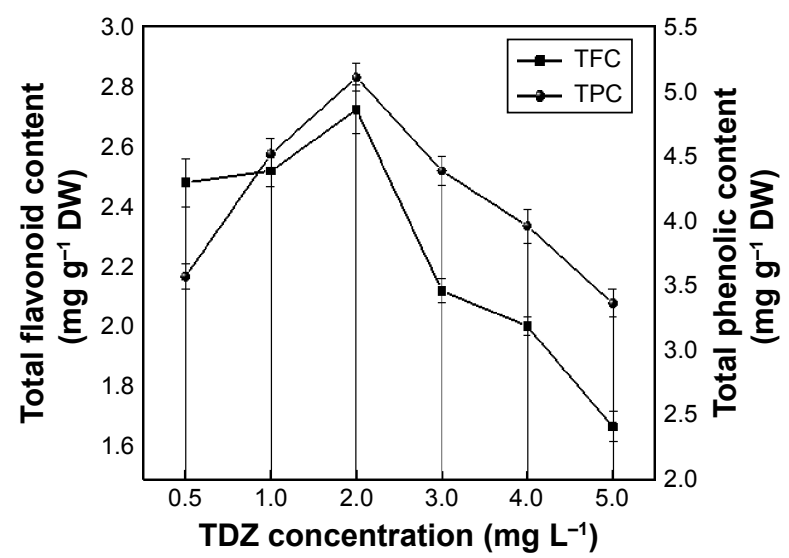

Figure 2 Total phenolic and flavonoid contents ( $\mathrm{mg} \mathrm{g}^{-1} \mathrm{DW}$ ) in callus cultures of Linum usitatissimum on MS medium supplemented with different concentrations of TDZ. Note: Values are mean \pm SE of three replicates.

Abbreviations: DW, dry weight; MS, Murashige and Skoog; SE, standard error; TDZ, thidiazuron; TFC, total flavonoid content; TPC, total phenolic content.
WPE- and TDZ-induced CE to find out the better reducing source. The formation of AgNPs in aqueous extracts can be monitored visually by color change from yellowish brown to dark brown. In our initial experiments, $1,000 \mu \mathrm{L}$ each of WPE and CE was mixed separately with $1 \mathrm{mM}$ SNS in different $\mathrm{v} / \mathrm{v}$ ratios $(1: 1,1: 2,1: 5$, and 1:10; extract/SNS). The reaction mixtures started turning brown immediately as they were mixed and continued turning darker with the passage of time. These reaction mixtures were kept at room temperature for 24 hours, but no further change in color was observed after 6 hours, suggesting that the color attained by all reaction mixtures was stable (Figure 3A and B). However, no color change was observed with WPE, CE, or SNS alone under the same conditions. In case of WPE-mediated biosynthesis of AgNPs, the only reaction mixture with 1:10 ratio (WPE/SNS) turned darker more rapidly compared to the rest of WPE/SNS reaction mixtures (Figure 3B). However, in the case of CEmediated biosynthesis of AgNPs, the reaction mixtures with $1: 2,1: 5$, and $1: 10$ ratios turned brown more rapidly than other reaction mixtures (Figure 3A), indicating that TDZ-induced $\mathrm{CE}$ is a better reducing source than WPE. This also showed that higher concentrations of SNS speed up the biosynthesis of AgNPs, which is in agreement with a previous study involving Agrimoniae herba extract as a reducing agent. ${ }^{39}$ The highest color intensity was observed in CE-mediated AgNP reaction mixture of 1:10 ratio. The change in color is the preliminary indication of biosynthesis of AgNPs, and this color change is due to the strong absorption of visible light due to excitation of surface plasmon resonance, which may affect the size and shape of AgNPs. ${ }^{16,39}$

\section{UV-vis spectroscopic characterization of AgNPs}

UV-vis spectroscopy is one of the vital techniques used for analyzing the formation and stability of AgNPs in aqueous solution. It is reported in the literature that AgNPs exhibit a characteristic surface plasmon resonance peak in the range of 400-480 nm wavelength. ${ }^{8,40}$ As shown in Figure 4, the WPE and CE mixed with SNS in different ratios showed a characteristic surface plasmon resonance between $410 \mathrm{~nm}$ and $426 \mathrm{~nm}$, indicating the presence of AgNPs in the solution. However, the 1:1 ratio of both types of reaction mixtures did not show any characteristic peak of AgNPs (Table 1). Highest absorbance with comparatively narrow peaks was observed when both extracts (WPE and CE) were mixed separately with SNS in 1:10 ratio, indicating higher yield of nanoparticles. The increase in absorbance intensity is due to increasing number of AgNPs formed as a result of reduction of silver ions. ${ }^{16,41}$ It is well known that the absorbance 
A

A

SNS

CE

1:1

1:2

$1: 5$

1:10

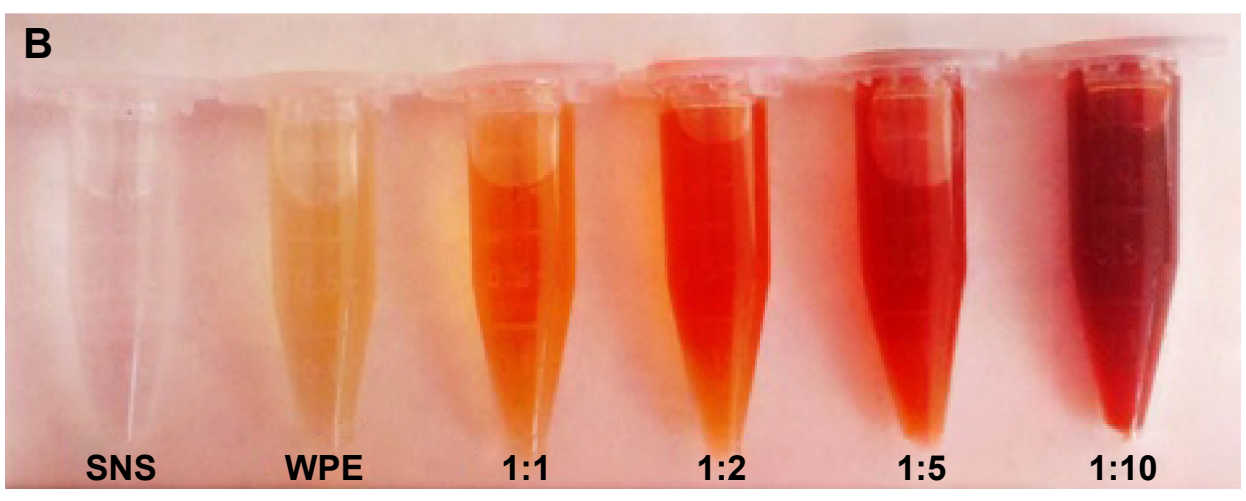

Figure 3 Biosynthesis of AgNPs.

Notes: (A) Reaction mixtures of CE/SNS in different ratios ( $v / v)$. (B) Reaction mixtures of WPE/SNS in different ratios ( $v / v$ ).

Abbreviations: AgNPs, silver nanoparticles; CE, callus extract; SNS, silver nitrate solution; WPE, whole plant extract.

A

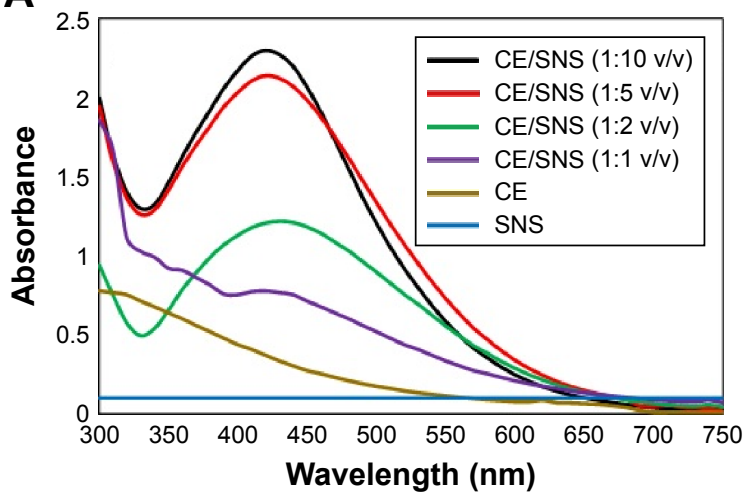

B

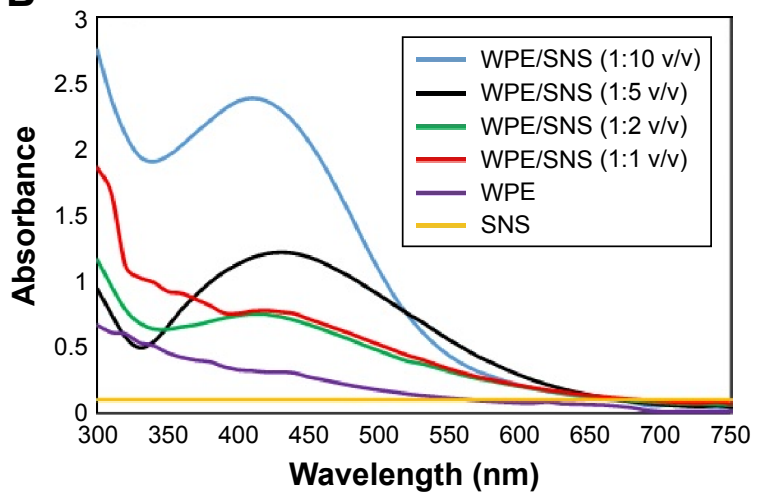

Figure 4 UV-vis spectra of AgNPs.

Notes: (A) CE/SNS reaction mixtures and (B) WPE/SNS reaction mixtures in different ratios (v/v) after 24 hours of incubation.

Abbreviations: UV-vis, ultraviolet-visible; AgNPs, silver nanoparticles; CE, callus extract; SNS, silver nitrate solution; WPE, whole plant extract.

Table I Synthesis formulation and UV-vis wavelength peaks of green-synthesized AgNPs

\begin{tabular}{|c|c|c|c|c|c|}
\hline \multicolumn{3}{|l|}{ WPE-mediated AgNPs } & \multicolumn{3}{|l|}{ CE-mediated AgNPs } \\
\hline $\begin{array}{l}\text { WPE (10 g/100 mL) + } \\
\text { SNS (I mM) }\end{array}$ & $\begin{array}{l}\text { WPE/SNS } \\
\text { ratios (v/v) }\end{array}$ & $\begin{array}{l}\text { Wavelength } \\
(\mathrm{nm})\end{array}$ & $\begin{array}{l}\text { CE }(10 \mathrm{~g} / 100 \mathrm{~mL})+ \\
\text { SNS }(1 \mathrm{mM})\end{array}$ & $\begin{array}{l}\text { CE/SNS } \\
\text { ratios (v/v) }\end{array}$ & $\begin{array}{l}\text { Wavelength } \\
(\mathrm{nm})\end{array}$ \\
\hline $100 \mu \mathrm{L}+1,000 \mu \mathrm{L}$ & $\mathrm{I}: 10$ & 410 & $100 \mu \mathrm{L}+1,000 \mu \mathrm{L}$ & $\mathrm{I}: 10$ & 418 \\
\hline $100 \mu \mathrm{L}+500 \mu \mathrm{L}$ & $1: 5$ & 422 & $100 \mu \mathrm{L}+500 \mu \mathrm{L}$ & $1: 5$ & 420 \\
\hline $100 \mu \mathrm{L}+200 \mu \mathrm{L}$ & $\mathrm{I}: 2$ & 412 & $100 \mu \mathrm{L}+200 \mu \mathrm{L}$ & $\mathrm{I}: 2$ & 426 \\
\hline $100 \mu \mathrm{L}+100 \mu \mathrm{L}$ & I:I & - & $100 \mu \mathrm{L}+100 \mu \mathrm{L}$ & I:I & - \\
\hline
\end{tabular}

Note: "-" symbols indicate no peaks were observed.

Abbreviations: UV-vis, ultraviolet-visible; AgNPs, silver nanoparticles; WPE, whole plant extract; CE, callus extract; SNS, silver nitrate solution. 
intensity mainly depends on the size and shape of AgNPs, and in general, absorbance peak decreases as the size of the nanoparticles increases. ${ }^{42}$

\section{Effect of reaction time on synthesis and stability of AgNPs}

To find out the reduction time of silver ions in the reaction mixtures, we investigated the absorbance intensities and wavelength peaks of reaction mixtures at different time intervals (10 minutes to 24 hours) by using UV-vis spectrophotometer. In the case of WPE/SNS reaction mixtures, an expansion of reaction time was accompanied with an obvious increase in the absorbance intensity before 6 hours, but no significant enhancement was found after 6 hours. This showed that the reduction of silver ions in WPE/SNS reaction mixtures was completed within 6 hours, with no further increase in absorption (Figure 5A). Similar results were also reported in the synthesis of AgNPs using the extract of Chrysanthemum indicum. ${ }^{34}$ However, in the case of TDZ-induced CE/SNS reaction mixtures, reduction of silver ions was completed within 2 hours, resulting in high yield of nanoparticles within a short time (Figure 5B). Among all the tested ratios of WPE and CE with SNS, 1:10 ratio of CE/SNS showed the highest absorbance intensity at $418 \mathrm{~nm}$ with a comparatively narrow peak and shorter reduction time. This might be due to enhancement of phytochemical reducing agents (TPC and TFC) in TDZ-induced CE as compared to WPE, resulting in rapid biosynthesis of AgNPs by speeding up the reduction of silver ions. These results are in agreement with those reported by Sheshadri et $\mathrm{al}^{43}$ who described the role of melatonin in the biosynthesis of AgNPs. Since 1:10 ratios of both types of reaction mixtures showed high absorption peak and complete reduction in lesser time period, we further proceeded with only these two reaction mixtures (1:10 ratio of WPE/SNS and CE/SNS). The stability of the synthesized AgNPs was examined by keeping the reaction mixtures at room temperature for 2 months, and it was found that the reaction mixtures showed peaks at the same wavelength with similar absorption intensity, which confirmed the stability of synthesized AgNPs (Figure 6). This showed that the phytochemicals present in the extracts not only act as reducing agents but also stabilize the synthesized AgNPs by preventing them from agglomeration. Similar results were also reported in the synthesis of AgNPs using the extract of A. herba. ${ }^{39}$

\section{FTIR spectroscopy analysis of AgNPs}

FTIR measurements were carried out to determine the possible interfacial phytochemicals involved in the reduction, capping, and stabilization of AgNPs. The results showed intense absorption peaks at $-3,691.10 \mathrm{~cm}^{-1}, 3,601.23 \mathrm{~cm}^{-1}$, $3,003.58 \mathrm{~cm}^{-1}, 2,934.07 \mathrm{~cm}^{-1}, 1,811.83 \mathrm{~cm}^{-1}, 1,714.03 \mathrm{~cm}^{-1}$, $1,323.34 \mathrm{~cm}^{-1}, 1,241.13 \mathrm{~cm}^{-1}, 1,096.44 \mathrm{~cm}^{-1}, 1,065.14 \mathrm{~cm}^{-1}$, $958.68 \mathrm{~cm}^{-1}, 860.01 \mathrm{~cm}^{-1}, 730.54 \mathrm{~cm}^{-1}, 653.07 \mathrm{~cm}^{-1}$, and $624.01 \mathrm{~cm}^{-1}$ for CE-mediated AgNPs (Figure 7A) and sharp absorption peaks at $-3,699.92 \mathrm{~cm}^{-1}, 3,600.82 \mathrm{~cm}^{-1}$, $3,003.76 \mathrm{~cm}^{-1}, 2,942.92 \mathrm{~cm}^{-1}, 1,811.87 \mathrm{~cm}^{-1}, 1,713.96 \mathrm{~cm}^{-1}$, $1,580.98 \mathrm{~cm}^{-1}, 1,407.93 \mathrm{~cm}^{-1}, 1,323.50 \mathrm{~cm}^{-1}, 1,182.37 \mathrm{~cm}^{-1}$, $1,141.01 \mathrm{~cm}^{-1}, 1,095.08 \mathrm{~cm}^{-1}, 1,065.07 \mathrm{~cm}^{-1}$, and $958.01 \mathrm{~cm}^{-1}$ for WPE-mediated AgNPs (Figure 7B). The absorption peaks in the region of $3,774.38-3,601.23 \mathrm{~cm}^{-1}$ were assigned to strong - $\mathrm{OH}$ stretching in alcohols, flavonoids, and phenolic compounds. ${ }^{3}$ The intense bands in the region of 2,934.07-2,891.01 $\mathrm{cm}^{-1}$ correspond to $\mathrm{O}-\mathrm{H}$ stretching
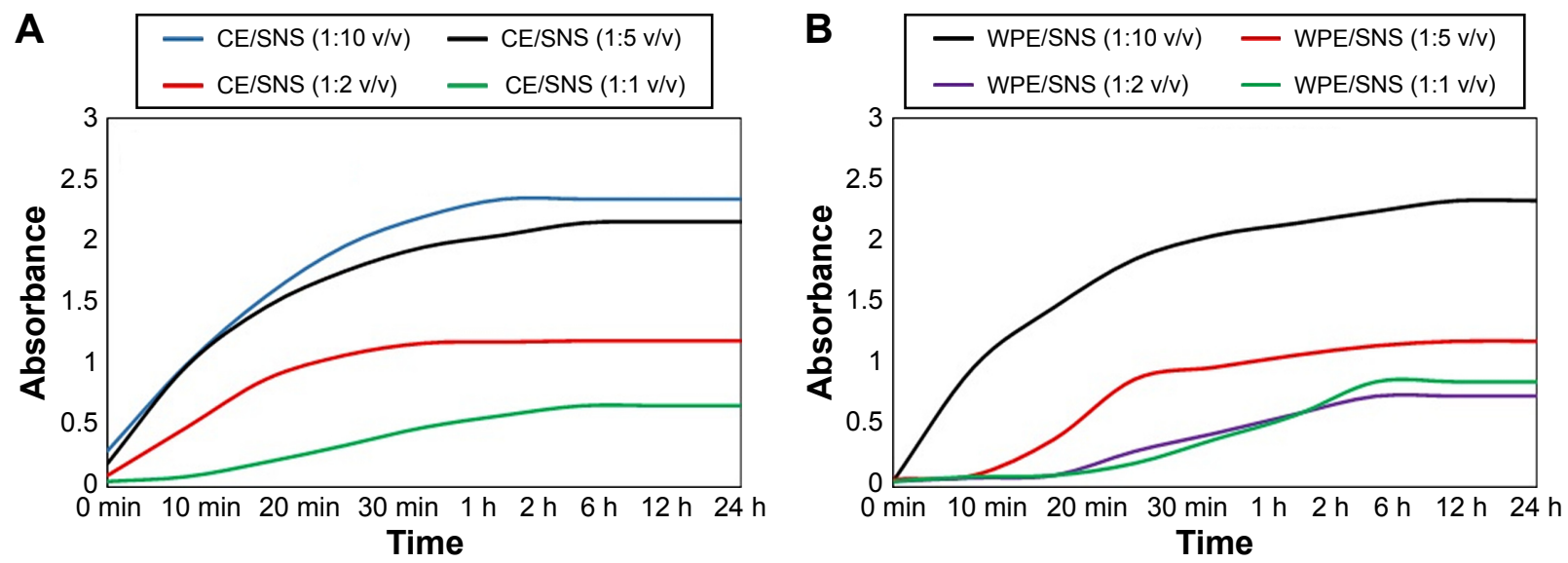

Figure 5 UV-vis absorbance profiles of AgNP synthesis as a function of time.

Notes: (A) CE/SNS reaction mixtures and (B) WPE/SNS reaction mixtures in different ratios $(\mathrm{v} / \mathrm{v})$.

Abbreviations: UV-vis, ultraviolet-visible; AgNPs, silver nanoparticles; CE, callus extract; SNS, silver nitrate solution; WPE, whole plant extract; min, minutes; h, hours. 


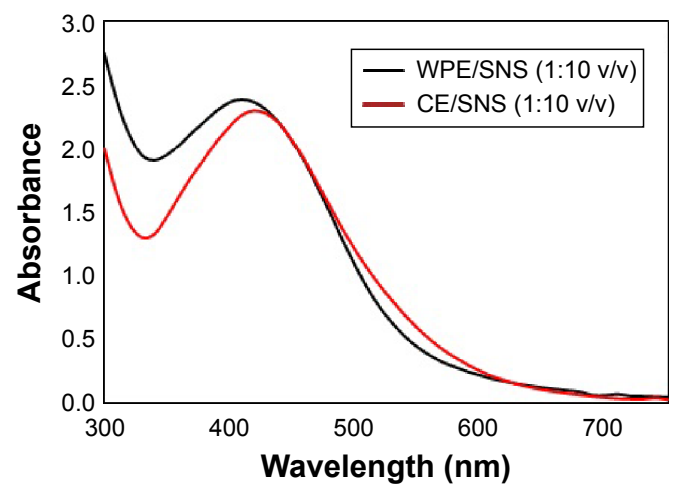

Figure 6 Evaluation of stability of synthesized AgNPs by using UV-vis spectroscopy after 2 months of incubation of reaction mixtures.

Abbreviations: AgNPs, silver nanoparticles; UV-vis, ultraviolet-visible; CE, callus extract; SNS, silver nitrate solution; WPE, whole plant extract. of carboxylic groups, while the broad band appearing at $1,714.03 \mathrm{~cm}^{-1}$ may be due to $\mathrm{C}=\mathrm{O}$ stretching of carbonyl group. The absorption band at $1,241.13 \mathrm{~cm}^{-1}$ corresponds to $\mathrm{C}-\mathrm{N}$ stretching of aliphatic amines, and the band at $1,065.14 \mathrm{~cm}^{-1}$ indicated $=\mathrm{C}-\mathrm{H}$ bending of alkenes. ${ }^{39,40}$ The peak around $653.07 \mathrm{~cm}^{-1}$ region represents the $-\mathrm{OH}$ bending of the phenolic group. ${ }^{34}$ These results showed that both types of synthesized AgNPs shared some common peaks in the region of $3,600-1,350 \mathrm{~cm}^{-1}$ but clearly different peaks in the region of 1,300-620 $\mathrm{cm}^{-1}$, suggesting the presence of some additional phytochemicals in CE (due to TDZinduced stress) compared to WPE. The present data strongly indicated the involvement of polyphenols, flavonoids,
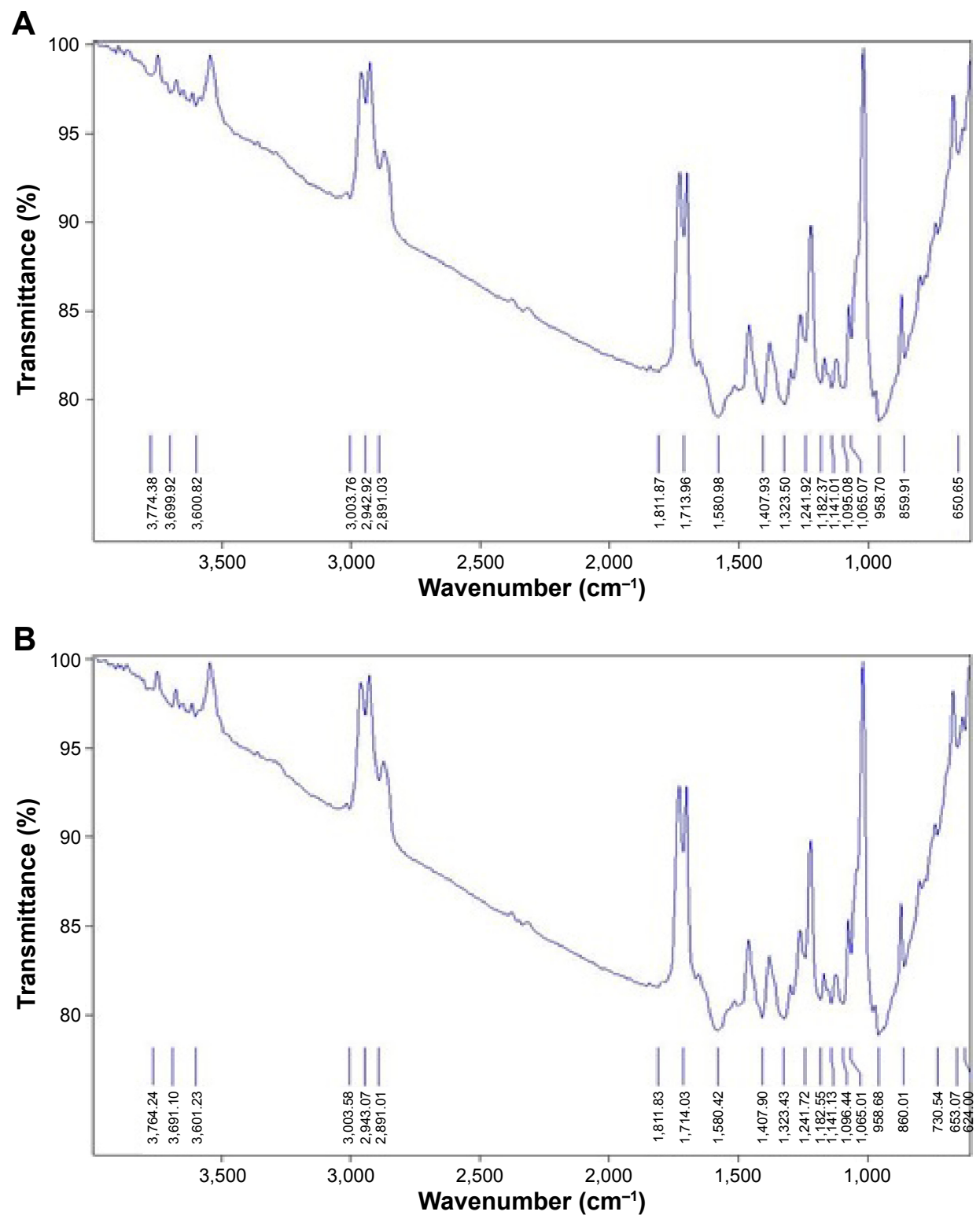

Figure 7 FTIR spectra of AgNPs.

Notes: (A) CE-mediated AgNPs. (B) WPE-mediated AgNPs.

Abbreviations: FTIR, Fourier-transform infrared; AgNPs, silver nanoparticles; CE, callus extract; WPE, whole plant extract. 

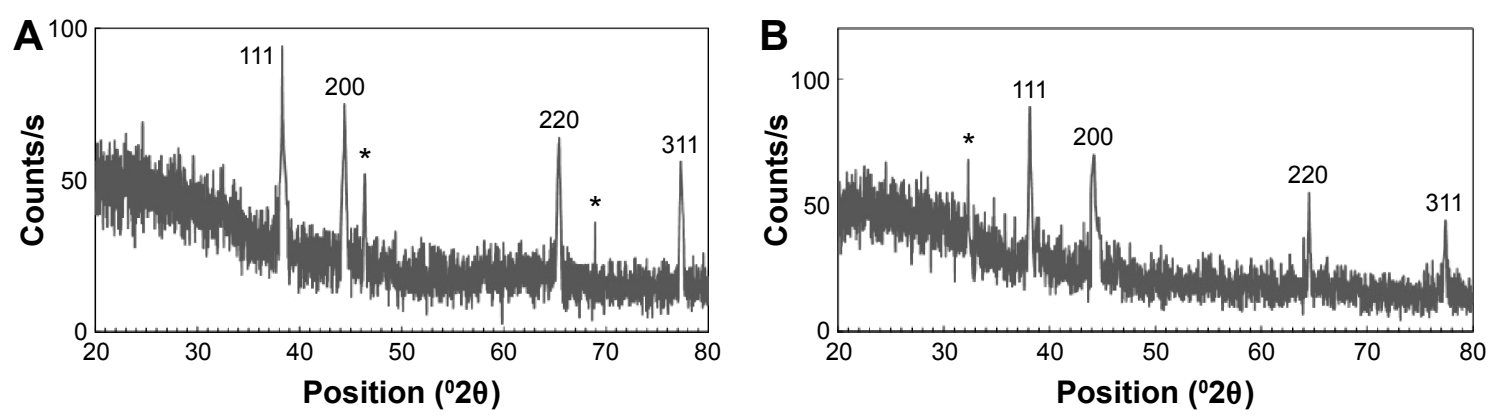

Figure 8 XRD patterns of AgNPs.

Notes: (A) CE-mediated AgNPs. (B) WPE-mediated AgNPs. *Indicates the unidentified peaks.

Abbreviations: XRD, X-ray diffraction; AgNPs, silver nanoparticles; CE, callus extract; WPE, whole plant extract; s, seconds.

aliphatic amines, and carbonyl compounds in the reduction and capping of AgNPs. Our results are in good agreement with other reports available in the literature, suggesting the involvement of aforementioned groups in the biosynthesis of AgNPs. ${ }^{11,13,15,16,41}$

\section{XRD analysis of AgNPs}

The crystalline nature of both types of synthesized AgNPs was confirmed by XRD analysis. XRD pattern of CEmediated AgNPs (Figure 8A) showed four distinct diffraction peaks at $38.31^{\circ}, 44.37^{\circ}, 65.41^{\circ}$, and $77.29^{\circ}$, which can be attributed to $111,200,220$, and 311 crystallographic planes of the face-centered cubic (FCC) crystalline silver. ${ }^{39}$ Similarly, the WPE-mediated AgNPs also showed four characteristic peaks at $38.13^{\circ}, 44.23^{\circ}, 64.53^{\circ}$, and $77.39^{\circ}$ attributed to $111,200,220$, and 311 crystalline planes of FCC crystalline structure of metallic silver (Figure $8 \mathrm{~B}$ ). ${ }^{3}$ Some unidentified crystalline peaks were also observed at $32.33^{\circ}, 46.37^{\circ}$, and $68.93^{\circ}$, which are also apparent in many other works in which the XRD pattern includes the relevant $2 \theta$ range. ${ }^{44}$ These peaks might be due to the presence of

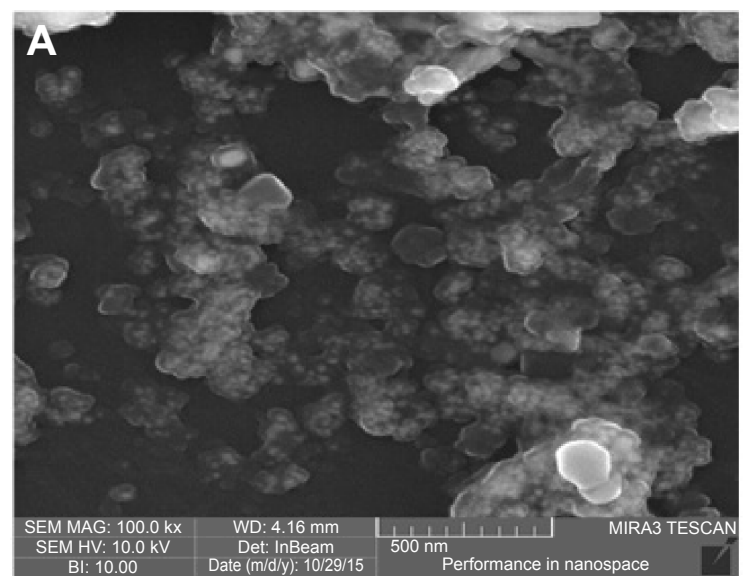

bioactive compounds on the surface of AgNPs, which are responsible for their capping. The average size of AgNPs was calculated by using the Debye-Scherrer equation by determining the full width at half maximum of the Bragg's reflection corresponding to the (111) crystalline plane of both types of synthesized AgNPs. ${ }^{45}$ The average crystalline sizes were calculated to be $\sim 19.61 \mathrm{~nm}$ for CE-mediated AgNPs and $54.19 \mathrm{~nm}$ for WPE-mediated AgNPs, which are in good agreement with the sizes calculated by SEM. These results clearly showed that both types of synthesized AgNPs exhibit the same crystalline structure (FCC) but vary in their sizes. CE-mediated AgNPs are smaller in size, compared to WPEmediated AgNPs, and hence are believed to be more efficient in their antimicrobial action because the smaller size makes the particles to penetrate more easily into the cells. ${ }^{46}$

\section{SEM and EDX analyses of AgNPs}

SEM technique was used to determine the size and morphology of synthesized AgNPs. SEM images (Figure 9A and B) clearly depict that both types of synthesized AgNPs were bead-like spherical in shape. However, the CE-mediated

Figure 9 SEM images of AgNPs.

Notes: (A) CE-mediated AgNPs. (B) WPE-mediated AgNPs. Scale bars $500 \mathrm{~nm}$.

Abbreviations: SEM, scanning electron microscopy; AgNPs, silver nanoparticles; CE, callus extract; WPE, whole plant extract.

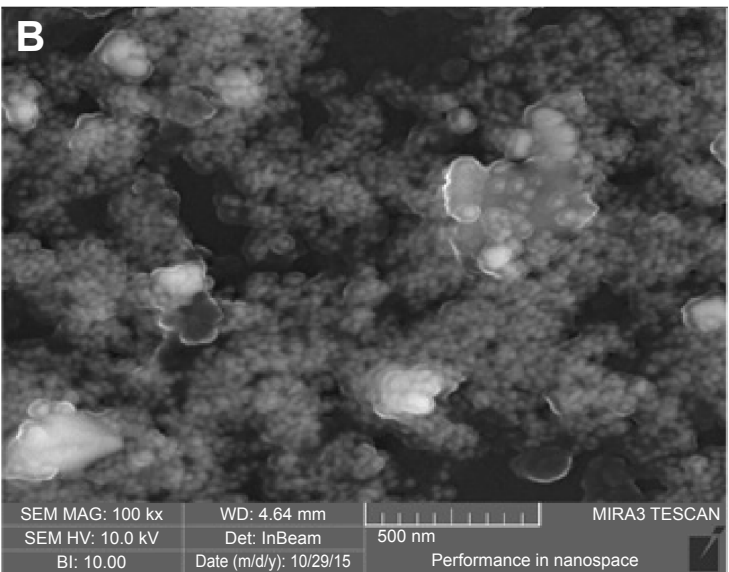


AgNPs were more dispersed than WPE-mediated AgNPs. Size calculation by SigmaScan Pro software attached with SEM showed that both types of synthesized AgNPs were clearly distinguishable owing to their size differences: 19-24 nm (CE-mediated AgNPs) and 49-54 nm (WPE-mediated AgNPs). These results revealed that the CE-mediated AgNPs were smaller in diameter and more scattered in distribution than that of WPE-mediated AgNPs. ${ }^{16}$ The SEM images also showed that the large bioactive compounds are attached to the surfaces of small AgNPs, making them stable by preventing agglomeration. The presence of metallic silver in the synthesized AgNPs was further confirmed by the EDX analysis. The EDX spectra (Figure 10A and B) showed strong peaks of metallic silver in the range of $3.0-4.0 \mathrm{keV}$. Metallic silver nanocrystal usually showed strong absorption spectra in the range of $2.5-4.0 \mathrm{keV}$, and similar results were also reported earlier. ${ }^{44}-47$

\section{Possible mechanism involved in biosynthesis of AgNPs}

The probable mechanism involved in the biosynthesis of AgNPs by plant metabolites is still largely unexplored. ${ }^{48}$ FTIR analysis of WPE- and CE-mediated AgNPs revealed that polyphenols, flavonoids, and carbonyl compounds are chiefly responsible for the reduction and stabilization of nanoparticles. Some important compounds of phenolic and flavonoid classes, which might be involved in the reduction of silver ions, are shown in Figure 11A. Determination of TPC and TFC showed that the WPE- and TDZ-induced CE are rich in phenolic and flavonoid contents, which are also in agreement with FTIR results. We, therefore, hypothesize the mechanism of reduction by showing the reduction of $\mathrm{Ag}^{+}$to $\mathrm{Ag}^{0}$ by the flavonoid standard compound (quercetin) through a redox reaction (Figure 11B). Additionally, the plant active compounds from extracts were also responsible for the

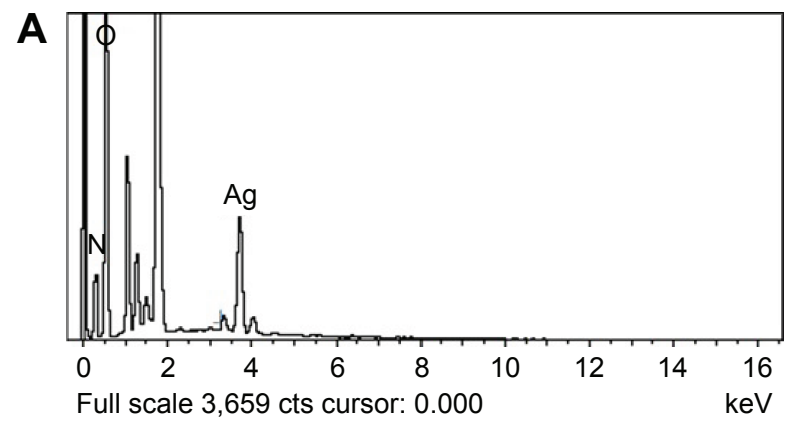

capping and stabilization of AgNPs (Figure 11C), as FTIR spectra of both WPE- and CE-mediated AgNPs showed the presence of almost similar functional groups. This proposed mechanism of AgNP biosynthesis is in good agreement with a previous report. ${ }^{3}$

\section{Antibacterial activities against multiple drug-resistant bacteria}

The antimicrobial efficacy of WPE- and CE-mediated AgNPs was examined against three highly multiple drug-resistant bacterial strains (E. coli, K. pneumoniae, and S. aureus) by using a standard antibiotic (ampicillin), positive control (SNS), and negative control (WPE and CE). WPE, CE, and SNS alone showed minimal levels of bactericidal activity as compared to both types of synthesized AgNPs (Figure 12). The zone of inhibition was measured in mm (Table 2), showing that all bacterial strains were more susceptible to CE-mediated AgNPs than to WPE-mediated AgNPs, which showed a moderate level of susceptibility. Surprisingly, both types of synthesized AgNPs demonstrated prominent results against $S$. aureus $(11.1 \mathrm{~mm}$ and $13.5 \mathrm{~mm})$ when compared to ampicillin $(1.11 \mathrm{~mm})$. These results (Figure 12 and Table 2) clearly showed that the CE-mediated AgNPs were more potent in their antibacterial action as compared to WPE-mediated AgNPs, suggesting the possible role of differences in their sizes. Similar potent antibacterial activity was reported by AgNPs, greenly synthesized by leaf and CE of Sesuvium portulacastrum. ${ }^{16}$ The size and shape of the synthesized nanoparticles play an important role in biomedical applications. ${ }^{34}$ Smaller sized nanoparticles are considered to be more efficient in their antimicrobial action because they can penetrate more easily into the cells. ${ }^{46}$ The smaller sized CE-mediated AgNPs (19-24 nm) showed enhanced zone of inhibition against the tested bacterial strains as compared to the larger sized WPE-mediated AgNPs (49-54 nm).

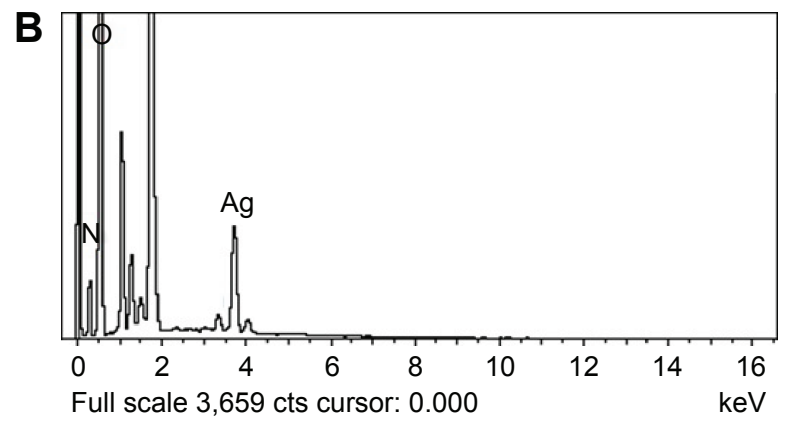

Figure 10 EDX spectra of AgNPs.

Notes: (A) CE-mediated AgNPs. (B) WPE-mediated AgNPs.

Abbreviations: EDX, energy dispersive X-ray; AgNPs, silver nanoparticles; CE, callus extract; WPE, whole plant extract; cts, counts time per second. 
A Epigallocatechi-3-gallate<smiles>Oc1cc(O)c2c(c1)O[C@H](C(O)(O)c1cc(O)c(O)c(O)c1)[C@H](c1cc(O)c(O)c(O)c1)O2</smiles><smiles>OC1Cc2ccccc2OC1c1ccccc1</smiles>

Flavan-3-ol

B<smiles>O=c1c(O)c(-c2ccc(O)c(O)c2)oc2cc(O)cc(O)c12</smiles>

Flavonoid (quercetin)
$(-)$ - epicatechin<smiles>Oc1cc(O)c2c(c1)O[C@H](c1ccc(O)c(O)c1)[C@H](O)C2</smiles><smiles>[O-]C1C=C(c2ccccc2)c2ccccc2O1</smiles>

Neoflavonoid
$(+)$ - catechin

\section{Quercetin}<smiles></smiles><smiles>OC1c2ccccc2OC(c2ccccc2)C1O</smiles>

Leucoanthocyanidin<smiles>O=c1c(O)c(-c2ccccc2)oc2ccccc12</smiles>

3-hydroxyflavone

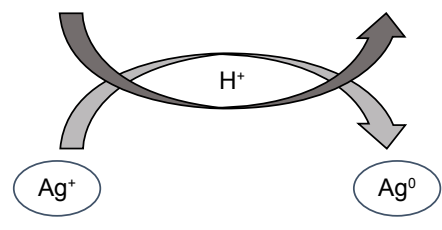

Cationic silver
Zerovalent silver (reduced form)<smiles>O=C1C=C(O)CC2=C1C(=O)C(O)C(c1ccc(O)c(O)c1)O2</smiles>

Oxidized form

C

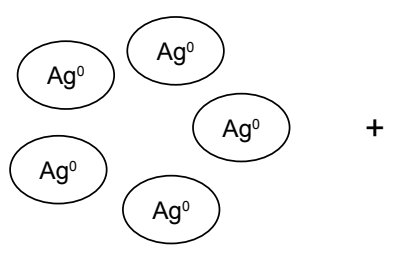

Reduced AgNPs

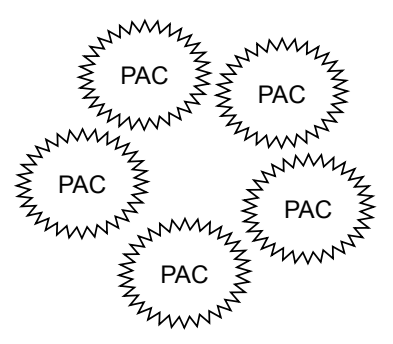

Plant active compounds

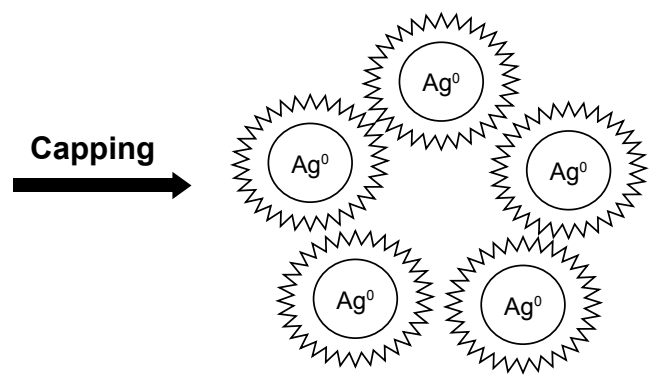

Stable AgNPs

Figure II Scheme of AgNP biosynthesis.

Notes: (A) Structures of some polyphenol and flavonoid biomolecules that might be involved in the reduction and stabilization of AgNPs. (B) Redox reaction showing mechanism of reduction of $\mathrm{Ag}^{+}$into $\mathrm{Ag}^{0}$ by using quercetin (flavonoid family). (C) Capping of $\mathrm{AgNPs}$ by plant active compounds. Abbreviation: AgNPs, silver nanoparticles.
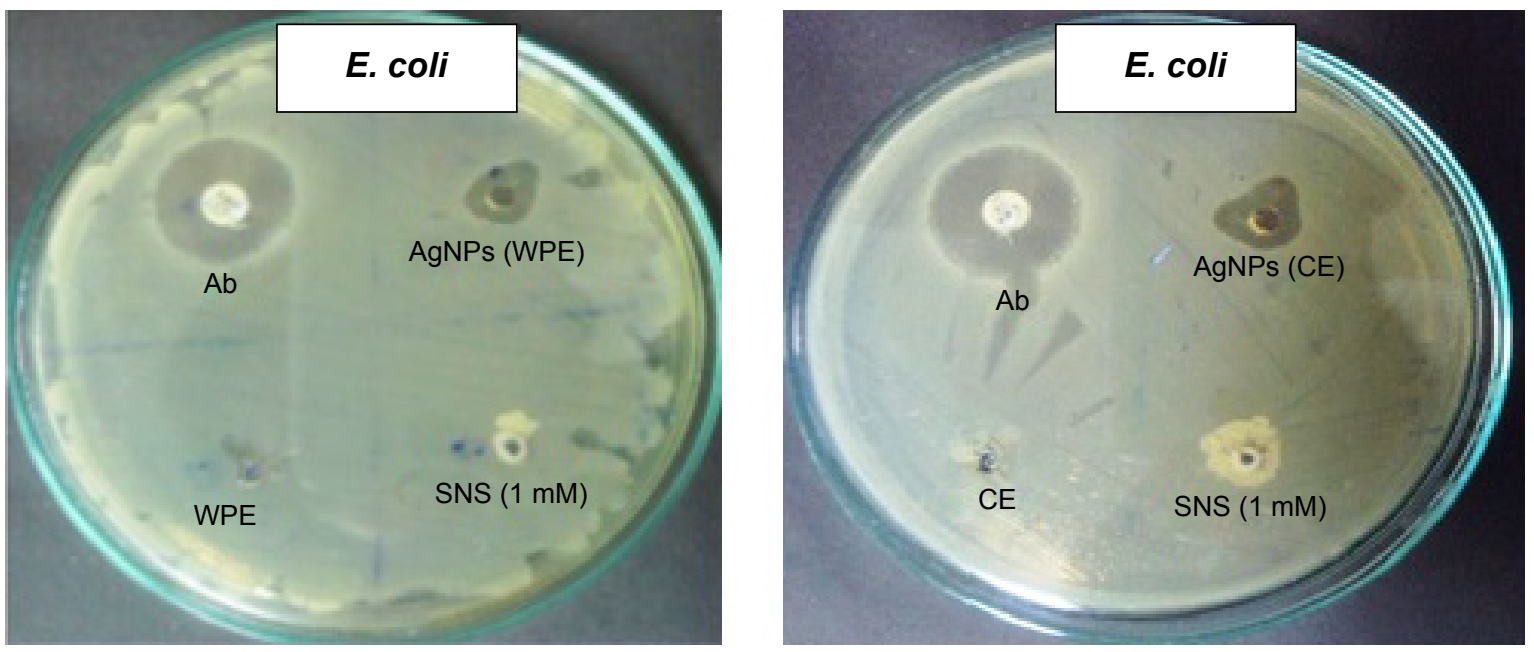

Figure 12 (Continued) 

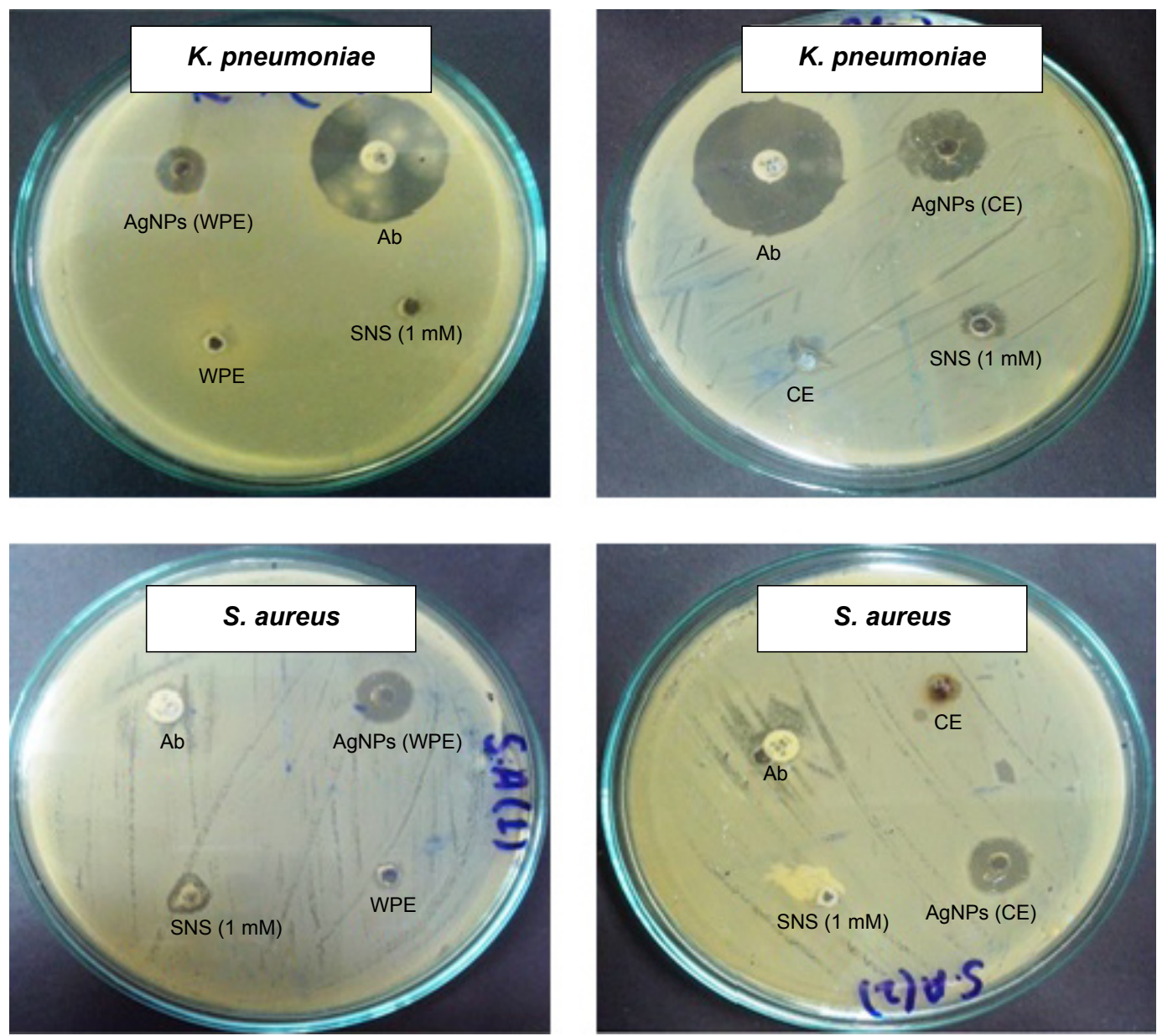

Figure 12 Antibacterial assay of AgNPs.

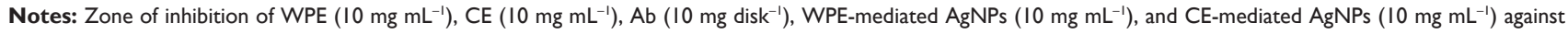
multiple drug-resistant bacterial strains was measured in $\mathrm{mm}$.

Abbreviations: AgNPs, silver nanoparticles; WPE, whole plant extract; CE, callus extract; Ab, antibiotic; E. coli, Escherichia coli; K. pneumoniae, Klebsiella pneumoniae; S. aureus, Staphylococcus aureus; SNS, silver nitrate solution.

The mechanism behind the antibacterial activity of AgNPs is not yet fully explored. Probably, the AgNPs exhibit the bactericidal activity by interacting with bacterial cell wall, deactivating the cellular enzymes, and causing disruptions in plasma membrane permeability. This disruption may result in the release of reactive oxygen species that can damage the DNA and proteins, eventually leading to the death of bacterial cells. ${ }^{49}$

\section{Conclusion}

In the present study, a novel protocol has been developed for rapid, safe, and cost-effective biosynthesis of

Table 2 Antibacterial activity of WPE- and CE-mediated AgNPs against multiple drug-resistant bacterial strains

\begin{tabular}{|c|c|c|c|c|c|c|}
\hline \multirow[t]{2}{*}{ Organism } & \multicolumn{6}{|c|}{ Zone of inhibition $(\mathrm{mm})\left(15 \mu \mathrm{L}\right.$ well $\left.^{-1}\right)$} \\
\hline & $\begin{array}{l}\text { I mM SNS, } \\
\text { mean } \pm \text { SD }\end{array}$ & $\begin{array}{l}\text { Antibiotics } \\
\left(10 \mathrm{mg} \mathrm{disk}^{-1}\right), \\
\text { mean } \pm \text { SD }\end{array}$ & $\begin{array}{l}\left.\text { WPE (10 } \mathrm{mg} \mathrm{mL}^{-1}\right) \\
\text { mean } \pm \text { SD }\end{array}$ & $\begin{array}{l}\text { CE }\left(10 \mathrm{mg} \mathrm{mL}^{-1}\right), \\
\text { mean } \pm \text { SD }\end{array}$ & $\begin{array}{l}\text { WPE-mediated } \\
\text { AgNPs }\left(10 \mathrm{mg} \mathrm{L}^{-1}\right), \\
\text { mean } \pm \text { SD }\end{array}$ & $\begin{array}{l}\text { CE-mediated } \\
\text { AgNPs }\left(10 \mathrm{mg} \mathrm{mL}^{-1}\right) \\
\text { mean } \pm \text { SD }\end{array}$ \\
\hline E. coli & $3.1 \pm 0.20$ & $18.1 \pm 1.08$ & $\mathrm{I} . \mathrm{I} \pm 0.02$ & $1.2 \pm 0.02$ & $1 \mathrm{I} .1 \pm 1.23$ & $13.2 \pm 1.42$ \\
\hline K. pneumoniae & $4.2 \pm 0.46$ & $28.3 \pm 1.02$ & $0.8 \pm 0.01$ & $1.3 \pm 0.01$ & $10.5 \pm 1.70$ & $16.2 \pm 1.93$ \\
\hline S. aureus & $7.2 \pm 0.38$ & $\mathrm{I} . \mathrm{I} \pm 0.0 \mathrm{I}$ & $0.9 \pm 0.01$ & $I . I \pm 0.01$ & $11.5 \pm 1.20$ & $13.1 \pm 1.04$ \\
\hline
\end{tabular}

Note: Values (mean $\pm S D$ ) indicate the replicates of three experiments.

Abbreviations: WPE, whole plant extract; CE, callus extract; AgNPs, silver nanoparticles; SNS, silver nitrate solution; SD, standard deviation; E. coli, Escherichia coli; K. pneumoniae, Klebsiella pneumoniae; S. aureus, Staphylococcus aureus. 
AgNPs, demonstrating the potential role of PGRs in the enhancement of phytochemicals in in vitro-derived cultures of plants. These phytochemicals act as reducing and capping agents in the biosynthesis of AgNPs, thus avoiding the use of hazardous chemicals. Present results clearly indicated the superiority of TDZ-induced CE over WPE for rapid biosynthesis of AgNPs. The CE-mediated AgNPs were smaller in size, more scattered in distribution, synthesized in short time, and possess high bactericidal activity than that of WPE-mediated AgNPs. The present study has opened new possible ways of utilizing in vitroderived cultures for synthesis of AgNPs. These chemicalfree synthesized AgNPs can be used in many biomedical applications and also for the successful development of drug delivery in future.

\section{Disclosure}

The authors report no conflicts of interest in this work.

\section{References}

1. Bhattacharyya D, Singh S, Satnalika N, Khandelwal A, Jeon S-H. Nanotechnology, big things from a tiny world: a review. Nanotechnology. 2009;2(3):29-38.

2. Kavitha K, Baker S, Rakshith D, et al. Plants as green source towards synthesis of nanoparticles. Int Res J Biol Sci. 2013;2(6):66-76.

3. Mittal AK, Bhaumik J, Kumar S, Banerjee UC. Biosynthesis of silver nanoparticles: elucidation of prospective mechanism and therapeutic potential. J Colloid Interface Sci. 2014;415:39-47.

4. Bar H, Bhui DK, Sahoo GP, Sarkar P, De SP, Misra A. Green synthesis of silver nanoparticles using latex of Jatropha curcas. Colloids Surf A Physicochem Eng Asp. 2009;339(1-3):134-139.

5. Baker S, Rakshith D, Kavitha KS, et al. Plants: emerging as nanofactories towards facile route in synthesis of nanoparticles. Bioimpacts. 2013;3(3):111-117.

6. Kowshik M, Ashtaputre S, Kharrazi S, et al. Extracellular synthesis of silver nanoparticles by a silver-tolerant yeast strain MKY3. Nanotechnology. 2003;14(1):95.

7. Galletti AMR, Antonetti C, Marracci M, Piccinelli F, Tellini B. Novel microwave-synthesis of $\mathrm{Cu}$ nanoparticles in the absence of any stabilizing agent and their antibacterial and antistatic applications. Appl Surf Sci. 2013;280:610-618.

8. Nazeruddin G, Prasad N, Waghmare SR, Garadkar KM, Mulla IS. Extracellular biosynthesis of silver nanoparticle using Azadirachta indica leaf extract and its anti-microbial activity. J Alloys Comp. 2014;583: 272-277.

9. Mukunthan KS, Balaji S. Cashew apple juice (Anacardium occidentale L.) speeds up the synthesis of silver nanoparticles. Int J Green Nanotechnol. 2012;4(2):71-79.

10. Li X, Xu H, Chen Z-S, Chen G. Biosynthesis of nanoparticles by microorganisms and their applications. J Nanomater. 2011;2011:8.

11. Armendariz V, Herrera I, Peralta-videa JR, et al. Size controlled gold nanoparticle formation by Avena sativa biomass: use of plants in nanobiotechnology. J Nanopart Res. 2004;6(4):377-382.

12. Li S, Shen Y, Xie A, et al. Green synthesis of silver nanoparticles using Capsicum annuum L. extract. Green Chem. 2007;9(8):852-858.

13. Sathishkumar M, Sneha K, Won SW, Cho C-W, Kim S, Yun Y-S. Cinnamon zeylanicum bark extract and powder mediated green synthesis of nanocrystalline silver particles and its bactericidal activity. Colloids Surf B. 2009; 73(2):332-338.
14. Malabadi RB, Meti NT, Mulgund GS, Nataraja K, Vijaya Kumar S. Synthesis of silver nanoparticles from in vitro derived plants and callus cultures of Costus speciosus (Koen.); assessment of antibacterial activity. Res Plant Biol. 2012;2(4):32-42.

15. Mude N, Ingle A, Gade A, Rai M. Synthesis of silver nanoparticles using callus extract of Carica papaya - a first report. J Plant Biochem Biotechnol. 2009;18(1):83-86.

16. Nabikhan A, Kandasamy K, Raj A, Alikunhi NM. Synthesis of antimicrobial silver nanoparticles by callus and leaf extracts from saltmarsh plant, Sesuvium portulacastrum L. Colloids Surf Biointerfaces. 2010;79(2): 488-493.

17. Sasheva P, Letkarska G, Ionkova I. Biotechnological production of podophyllotoxin and podophyllotoxin-related lignans in cultures of Linum thracicum Degen. Comptes Rendus de l'Academie bulgare des Sciences. 2013;66(10):1445-1450.

18. Coste A, Vlase L, Halmagyi A, Deliu C, Coldea G. Effects of plant growth regulators and elicitors on production of secondary metabolites in shoot cultures of Hypericum hirsutum and Hypericum maculatum. Plant Cell Tiss Org Cult. 2011;106(2):279-288.

19. Gaspar T, Kevers C, Penel C, Greppin H, Reid DM, Thorpe TA. Plant hormones and plant growth regulators in plant tissue culture. In Vitro Cell Dev Biol Plant. 1996;32(4):272-289.

20. Guo B, Abbasi BH, Zeb A, Xu LL, Wei YH. Thidiazuron: a multidimensional plant growth regulator. Afr J Biotechnol. 2013;10(45): 8984-9000.

21. Khan MA, Abbasi BH, Shinwari ZK. Thidiazuron enhanced regeneration and silymarin content in Silybum marianum L. Pak J Bot. 2014;46(1): 185-190.

22. Baghel S, Bansal YK. Thidiazuron promotes in vitro plant regeneration and phytochemical screening of Guizotia abyssinica Cass. A multipurpose oil crop. WJPPS. 2014;4:1193-1217.

23. Adlercreutz H. Lignans and human health. Crit Rev Clin Lab Sci. 2007; 44(5-6):483-525.

24. Kosińska A, Penkacik K, Wiczkowski W, Amarowicz R. Presence of caffeic acid in flaxseed lignan macromolecule. Plant Foods Hum Nutr. 2011;66(3):270-274.

25. Szewczyk M, Abarzua S, Schlichting A, et al. Effects of extracts from Linum usitatissimum on cell vitality, proliferation and cytotoxicity in human breast cancer cell lines. J Med Plants Res. 2014;8(5): 237-245.

26. Hano C, Renouard S, Molinié R, et al. Flaxseed (Linum usitatissimum L.) extract as well as (+)-secoisolariciresinol diglucoside and its mammalian derivatives are potent inhibitors of $\alpha$-amylase activity. Bioorg Med Chem Lett. 2013;23(10):3007-3012.

27. Palla AH, Khan NA, Bashir S, Ur-Rehman N, Iqbal J, Gilani AH. Pharmacological basis for the medicinal use of Linum usitatissimum (Flaxseed) in infectious and non-infectious diarrhea. JEthnopharmacol. 2015;160:61-68.

28. Prasad K. Dietary flax seed in prevention of hypercholesterolemic atherosclerosis. Atherosclerosis. 1997;132(1):69-76.

29. Rickard-Bon SE, Thompson LU. The role of flaxseed lignans in hormone-dependent and independent cancer. In: Muir AD, Westcott ND, editors. Flax: The Genus Linum. Boca Raton, FL: CRC Press; 2003: 181-203.

30. Ali M, Abbasi BH. Thidiazuron-induced changes in biomass parameters, total phenolic content, and antioxidant activity in callus cultures of Artemisia absinthium L. Appl Biochem Biotechnol. 2014;172(5): 2363-2376.

31. Murashige T, Skoog F. A revised medium for rapid growth and bio assays with tobacco tissue cultures. Physiol Plant. 1962;15(3):473-497.

32. Velioglu Y, Mazza G, Gao L, Oomah BD. Antioxidant activity and total phenolics in selected fruits, vegetables, and grain products. J Agric Food Chem. 1998;46(10):4113-4117.

33. Chang C-C, Yang M-H, Wen H-M, Chern J-C. Estimation of total flavonoid content in propolis by two complementary colorimetric methods. J Food Drug Anal. 2002;10(3):178-182. 
34. Arokiyaraj S, Arasu MV, Vincent S, et al. Rapid green synthesis of silver nanoparticles from Chrysanthemum indicum L and its antibacterial and cytotoxic effects: an in vitro study. Int J Nanomedicine. 2014;9: 379-388.

35. Duncan DB. Multiple range and multiple F tests. Biometrics. 1955;11(1): $1-41$.

36. Ali M, Abbasi BH. Production of commercially important secondary metabolites and antioxidant activity in cell suspension cultures of Artemisia absinthium L. Ind Crops Prod. 2013;49:400-406.

37. Magdi HM, Bhushan B. Extracellular biosynthesis and characterization of gold nanoparticles using the fungus Penicillium chrysogenum. Microsyst Technol. 2015;21(10):2279-2285.

38. Mohanpuria P, Rana NK, Yadav SK. Biosynthesis of nanoparticles: technological concepts and future applications. J Nanopart Res. 2008; 10(3):507-517.

39. Qu D, Sun W, Chen Y, Zhou J, Liu C. Synthesis and in vitro antineoplastic evaluation of silver nanoparticles mediated by Agrimoniae herba extract. Int J Nanomedicine. 2014;9:1871-1882.

40. Gogoi N, Babu PJ, Mahanta C, Bora U. Green synthesis and characterization of silver nanoparticles using alcoholic flower extract of Nyctanthes arbortristis and in vitro investigation of their antibacterial and cytotoxic activities. Mater Sci Eng C. 2015;46:463-469.

41. Bar H, Bhui DK, Sahoo GP, Sarkar P, Pyne S, Misra A. Green synthesis of silver nanoparticles using seed extract of Jatropha curcas. Colloids Surf A Physicochem Eng Asp. 2009;348(1-3):212-216.

42. Mock J, Barbic M, Smith DR, Schultz DA, Schultz S. Shape effects in plasmon resonance of individual colloidal silver nanoparticles. J Chem Phys. 2002;116(15):6755-6759.
43. Sheshadri SA, Sriram S, Balamurugan P, et al. Melatonin improves bioreductant capacity and silver nanoparticles synthesis using Catharanthus roseus leaves. RSC Adv. 2015;5(59):47548-47554.

44. Kumar R, Roopan SM, Prabhakarn A, Khanna VG, Chakroborty S. Agricultural waste Annona squamosa peel extract: biosynthesis of silver nanoparticles. Spectrochim Acta A Mol Biomol Spectrosc. 2012; 90:173-176.

45. Mie R, Samsudin MW, Din LB, Ahmad A, Ibrahim N, Adnan SN. Synthesis of silver nanoparticles with antibacterial activity using the lichen Parmotrema praesorediosum. Int J Nanomedicine. 2014;9:121-127.

46. Morones JR, Elechiguerra JL, Camacho A, et al. The bactericidal effect of silver nanoparticles. Nanotechnology. 2005;16(10):2346-2353.

47. Jeeva K, Thiyagarajan M, Elangovan V, Geethac N, Venkatachalam P. Caesalpinia coriaria leaf extracts mediated biosynthesis of metallic silver nanoparticles and their antibacterial activity against clinically isolated pathogens. Ind Crops Prod. 2014;52:714-720.

48. Pourmortazavi SM, Taghdiri M, Makari V, Rahimi-Nasrabadi M. Procedure optimization for green synthesis of silver nanoparticles by aqueous extract of Eucalyptus oleosa. Spectrochim Acta A. 2015;136: 1249-1254.

49. Chaloupka K, Malam Y, Seifalian AM. Nanosilver as a new generation of nanoproduct in biomedical applications. Trends Biotechnol. 2010;28(11):580-588.
International Journal of Nanomedicine

\section{Publish your work in this journal}

The International Journal of Nanomedicine is an international, peerreviewed journal focusing on the application of nanotechnology in diagnostics, therapeutics, and drug delivery systems throughout the biomedical field. This journal is indexed on PubMed Central, MedLine, CAS, SciSearch ${ }^{\circledR}$, Current Contents ${ }^{\circledR} /$ Clinical Medicine,

\section{Dovepress}

Journal Citation Reports/Science Edition, EMBase, Scopus and the Elsevier Bibliographic databases. The manuscript management system is completely online and includes a very quick and fair peer-review system, which is all easy to use. Visit http://www.dovepress.com/ testimonials.php to read real quotes from published authors. 